\title{
Device Difficult to Maintain
}

National Cancer Institute

\section{Source}

National Cancer Institute. Device Difficult to Maintain. NCI Thesaurus. Code C79146.

Problem associated with the user's ability to service a medical device according to the manufacturer specifications relating to a routine device maintenance, i.e., periodic inspection, failure detection, repair, and care of the device to sustain or restore acceptable operating conditions. 